\title{
A educação ambiental no cotidiano escolar: relatos do centro de ensino médio
}

A educação ambiental surge como um dos temas mais discutidos atualmente devido ao papel social que desempenha. Nesse contexto, a escola possui papel privilegiado por promover a informação que auxilia na percepção ambiental dos alunos, além de exercer o trabalho educacional que compõe medidas emergenciais O objetivo deste trabalho foi estudar o desenvolvimento da educação ambiental em uma escola pública do município de Guaraí/To, analisando a gestão escolar para identificar se a mesma proporciona a educação ambiental em suas ações. A pesquisa contou com o total de 49 participantes, e para a coleta dos dados qualitativos e quantitativos, foi aplicado um questionário com perguntas predeterminadas, objetivas e discursivas, procurando diagnosticar a percepção ambiental dos discentes e da comunidade escolar. Para a análise dos dados coletados foi estabelecido o método estatístico descritivo. Os resultados demonstram que a escola não adota a educação ambiental conforme a orientação dos PCNs, o que resulta na fragilidade da percepção ambiental dos entrevistados, revelando a necessidade de melhorias no desenvolvimento da temática ambiental e o comprometimento da gestão com a transversalidade entre os conteúdos. A percepção ambiental bem elaborada pode estimular a transformação social que resulta na mudança de postura dos indivíduos em sociedade, garantindo o equilíbrio ambiental necessário à garantia dos recursos para as próximas gerações.

Palavras-chave: Educação ambiental; Percepção ambiental; Escola; PCNs.

\section{Environmental education in the school daily life: stories from the middle school}

Environmental education emerges as one of the most discussed themes today because of the social role it plays. In this context, the school has a privileged role to promote the information that assists in the environmental perception of the students, besides carrying out the educational work that composes emergency measures. The objective of this work was to study the development of environmental education in a public school in the municipality of Guaraí/TO, analyzing school management to identify whether it provides environmental education in its actions. The survey consisted of a total of 49 participants, and for the collection of qualitative and quantitative data, a questionnaire was applied with predetermined, objective and discursive questions, trying to diagnose the environmenta perception of the students and the school community. For the analysis of the data collected, the descriptive statistical method was established. The results show that the school does not adopt environmental education according to the orientation of the NCPs, which results in the fragility of the environmental perception of the interviewees, revealing the need for improvements in the development of the environmental theme and the commitment of management to the transversality between contents. Well-designed environmental perception can stimulate the social transformation that results in changing the posture of individuals in society, ensuring the environmental balance necessary to guarantee resources for the next generations.

Keywords: Environmental education; Environmental perception; School; PCNs.

Topic: Planejamento, Gestão e Políticas Públicas Ambientais

Reviewed anonymously in the process of blind peer.

Alessandro Santos Nascimento

Faculdade Guaraí, Brasil

http://lattes.cnpq.br/7291199167740627

alessandro_crvg@hotmail.com

Layanne Rodrigues Almeida

Faculdade Guaraí, Brasil

http://lattes.cnpq.br/4348503432949930

layannerodrigues4@gmail.com

Aluísio Vasconcelos Carvalho iD

Faculdade Guaraí, Brasil

http://lattes.cnpq.br/5200758055263996

http://orcid.org/0000-0002-3793-3133

aluisiovasconcelos@gmail.com
Received: 18/12/2017

Approved: $27 / 12 / 2017$
Referencing this:

NASCIMENTO, A. S.; ALMEIDA, L. R.; CARVALHO, A. V.. A educação ambiental no cotidiano escolar: relatos do centro de ensino médio. Natural Resources, v.7, n.2, p.11-22, 2017. DOI: http://doi.org/10.6008/SPC2237-9290.2017.002.0002 


\section{INTRODUÇÃO}

Ao longo da história, a humanidade vem desvendando, conhecendo e modificando a natureza para extrair o seu melhor recurso. Dessa mesma maneira, outras formas de vida foram extintas, que por conseguinte fez surgir novas necessidades estabelecendo a criação de técnicas diferentes para supri-las, decorrentes do consumo e produção (SANTOS et al., 2004).

Nesta perspectiva, Quadros (2007) afirma que a sociedade não pode estar centrada apenas no agora sem analisar os resultantes de suas ações para o futuro, tornando a educação ambiental necessária por ser um tema de relevância social. A educação ambiental, tem sido tema constantemente discutido devido à necessidade de melhoria do planeta onde vivemos. Nota-se que existe uma regressão na qualidade de vida de um modo geral muito em conta de obrigações diárias que tornam o tempo cada vez mais curto em função de inúmeros compromissos (GUEDES, 2006). De fato, percebe-se que os problemas ambientais são resultados de práticas em longo prazo, e o que se apresenta hoje são agravamentos ocasionados pela humanidade (DIAS, 2004).

Neste sentido, Gomes (2006) diz ser necessário mudanças na forma de pensar e agir das pessoas, papel este em que a educação é fundamental para a construção de ações éticas, responsáveis e solidárias em relação ao meio ambiente. A escola assume o papel privilegiado para estabelecer conexões e promover a informação como alternativa para criar novas posturas, concepções e estimular os alunos a serem cientes de suas responsabilidades cidadãs, além de principalmente gerar a percepção como integrantes do ambiente, o que demonstra a importância que a educação formal possui para o desenvolvimento de atitudes e valores comprometidos com a sustentabilidade, seja ela social ou ecológica (LIMA, 2004).

Carvalho (2006) acredita que o trabalho educacional compõe as medidas essenciais de caráter emergencial, onde os desequilíbrios ecológicos estão relacionados às condutas humanas prejudiciais impulsionadas por princípios consumistas resultantes da sociedade capitalista, e ainda o uso abusivo dos bens naturais como a água, solo e florestas. Porém, pesquisas demonstram que a educação ambiental está sendo trabalhada nas escolas de maneira transversal agindo como modeladora para a nova cultura da organização escolar (MAURíCIO, 2009). Mas, para que esta transversalidade tenha efeito sobre as práticas pedagógicas, é importante que haja a quebra de barreiras existente entre as disciplinas, assim como as barreiras entre os profissionais docentes (CUBA, 2010).

Saraiva et al. (2008) afirmam que, em prática, a educação ambiental não tem sido transversalizada nas ações pedagógicas, ficando apenas na teoria, muitas vezes por falta de incentivo ao professor e conhecimento do mesmo nesta área. Devido o estado atual do ambiente natural, a escola, responsável pelo papel de modeladora social, deve informar, pesquisar e garantir a formação de futuros gestores da sociedade humana deixando claro a necessidade atual de uma gestão escolar voltada para o desenvolvimento e aplicação da educação ambiental (ARAUJO et al., 2010).

Trevisol (2003) acredita na mudança do indivíduo, onde o mesmo possa rever as suas concepções e hábitos, e assim formar pessoas que mantenham uma relação sustentável com o meio onde vivem. De fato, 
estudos realizados demonstram que a educação ambiental será eficaz apenas se os alunos desenvolverem a percepção do mundo a sua volta, apresentando uma consciência crítica que busca solucionar os problemas (KINDELL et al., 2006). O presente artigo tem como objetivo analisar o desenvolvimento da educação ambiental no espaço escolar, como parte dos temas transversais e de modo que todos os envolvidos percebam a sua importância.

\section{MATERIAIS E MÉTODOS}

\section{Área de estudo}

O presente trabalho foi realizado no município de Guaraí, interior do Estado do Tocantins, situado na região Norte a 178km da capital, Palmas (IBGE, 2015). Ainda de acordo com as informações contidas na plataforma do Instituto Brasileiro de Geografia e Estatística - IBGE, o município encontra-se nas

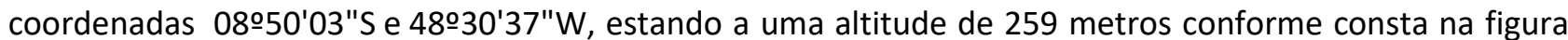
1A. A área de coleta dos dados foi o Centro de Ensino Médio Oquerlina Torres, que oferece o ensino médio regular da 1a a 3을érie, de acordo com a parte B da figura 1.

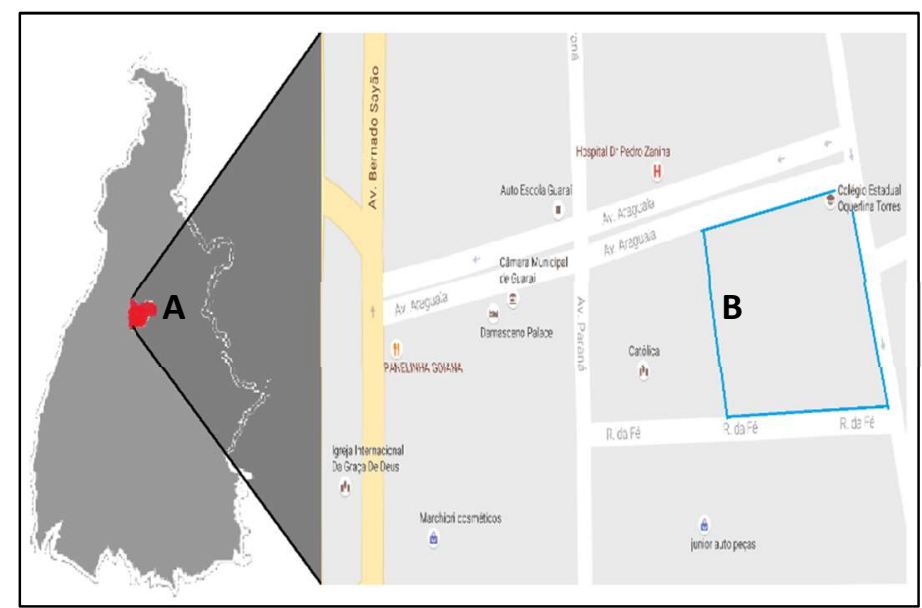

Figura 1: A) Localização do Município de Guaraí dentro do estado do Tocantins; B) Área de estudo: Colégio Estadual Oquerlina Torres em Guaraí/TO.

\section{Coleta de dados}

A coleta de dados foi baseada no método de Marconi et al. (2008), em que se obteve os dados qualitativos e quantitativos através da aplicação de questionário, seguindo a metodologia de entrevistas semiestruturadas, nas quais as perguntas a serem feitas são pré-determinadas. Os questionários vêm sendo um método de entrevista muito utilizado, podendo ser inseridos em diversos campos de pesquisa com o objetivo de levantar a relação homem/ecossistema em prol da conservação, em função de apresentar simultaneamente uma eficiência na abordagem e coleta de informações (CALDAS, 2003).

Para a aplicação do questionário, foram selecionados os alunos da primeira, segunda e terceira série do ensino médio, além de alguns funcionários, sendo todos do período matutino. Os roteiros elaborados 
foram compostos por questões abertas, em que o entrevistado pode expressar a sua opinião, e fechadas, com opções de múltipla escolha, proporcionando várias vertentes ao mesmo assunto (MARCONI et al., 2008).

Foram abordadas 11 questões que caracterizam a problemática do artigo segundo a metodologia de Moreira et al. (2008) com adaptações. No início das entrevistas houve a explicação prévia, ressaltando os objetivos da pesquisa e a importância da participação voluntária. Utilizou-se gravador de voz e anotações para registrar as conversas, que posteriormente foram transcritas e encaminhadas para a tabulação (PALMA, 2005)

Durante a pesquisa de campo, percebeu-se a importância do uso de estratégias que garantissem a maior precisão das investigações. Seguindo a orientação metodológica de White (1977), utilizou-se técnicas baseadas estrategicamente em ouvir, perguntar e observar. Como ponto de partida, adotou-se o procedimento ouvir, em que os interlocutores pudessem expressar-se livremente, revelando as suas percepções sem a influência dos pesquisadores, de forma a compreender os participantes do levantamento perceptivo (WHITE, 1977).

Para a pesquisa, foi utilizada uma linguagem comum em preocupação ao fácil entendimento e interpretação dos entrevistados que não dominam a linguagem acadêmica, em busca clara e objetiva dos resultados, assegurando o anonimato e sigilo de todos os envolvidos. As questões contidas no questionário buscavam os elementos socioambientais dos entrevistados bem como informações acerca dos trabalhos desenvolvidos no ambiente escolar.

\section{Análise de dados}

O método estatístico utilizado foi descritivo com análise qualitativa e quantitativa (MICHEL, 2005). Os dados obtidos através das entrevistas foram expressos no Microsoft Word 2010, para serem tabulados e posteriormente convertidos em tabelas e gráficos, de forma a facilitar a compreensão dos resultados. Nas questões abertas, foram levantadas palavras-chave e agrupadas conforme as respostas semelhantes; já nas questões fechadas, houve o agrupamento de acordo com a frequência das respostas (CUNHA et al., 2007).

\section{RESULTADOS E DISCUSSÕES}

\section{Perfil dos entrevistados}

Os 49 entrevistados, dentre os quais 31 são mulheres e 18 homens, possuem idade aproximada entre 14 e 50 anos, a maioria natural do município. O maior número de entrevistados concentra-se na 1a série sendo $37 \%$ do total, na 2 o série foram entrevistados $20 \%$, na 3a série $25 \%$ e entre os funcionários (professores, administradores) foram entrevistados 18\%, como mostra a figura 2.

Entre os entrevistados nessa pesquisa, dos quais $63 \%$ são mulheres e $37 \%$ homens, grande parte não realizam atividades trabalhistas, exceto os funcionários da escola. A maioria dos discentes atuam apenas como estudantes, sendo que, atualmente, uma pequena quantidade possui emprego em áreas como comércio, oficinas, drogarias, restaurantes, agropecuária e outras atividades características da região. A 
unidade de ensino recebe alunos provenientes da zona urbana, rural e diversas classes sociais, apresentando funcionários experientes e com períodos variados de atuação.

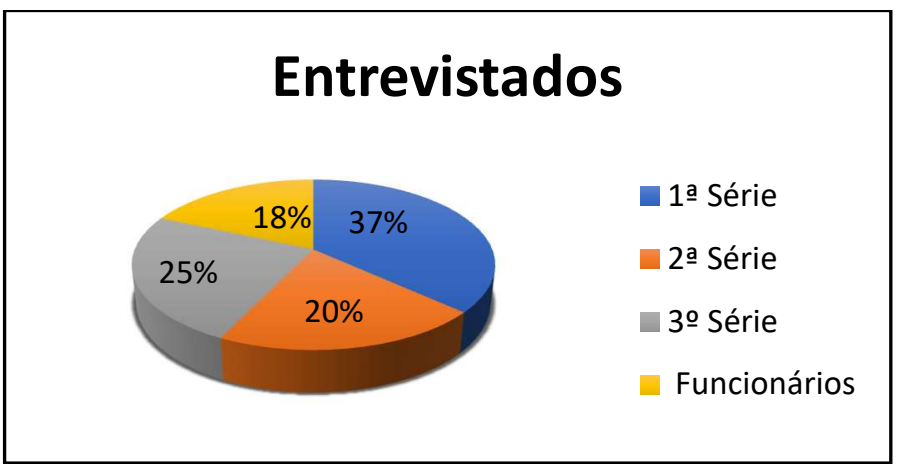

Figura 2: Percentual dos participantes da entrevista de acordo com o nível de ensino e papel desempenhado no Centro de Ensino Médio Oquerlina Torres.

De acordo com o IBGE (2013), a agropecuária exerce grande influência sobre a economia do município de Guaraí, o que resulta nos altos índices do produto interno bruto (PIB), arrecadando cerca de $\mathrm{R} \$ 39.788,00$ em atividades voltadas a agropecuária, $\mathrm{R} \$ 32.599,00$ em indústria e $\mathrm{R} \$ 228.734,00$ em serviços.

A escola atende a uma clientela heterogênea, pois se trata de um Centro de Ensino Médio que acolhe ao diverso número de migrantes oriundos de todo o Brasil. Devido ao alto percentual de urbanização do município e o grande número de unidades escolares, percebeu-se que o fator de desenvolvimento urbano pode revelar inúmeras questões sobre o ambiente natural, por ser o nível de ensino com menos estudos em educação ambiental se comparado ao ensino fundamental (FONSECA et al., 2005), optou-se pela instituição de ensino médio regular como público alvo, sendo que, este é o segmento de ensino que apresenta o maior crescimento nos últimos anos (MEC, 1999).

\section{A percepção dos entrevistados quanto ao significado de educação ambiental}

Cerca de $49 \%$ dos entrevistados entendem que educação ambiental significa cuidar do meio ambiente (preservação); assim sendo, 14\% dos interlocutores afirmam que educação ambiental é o estudo e conhecimento sobre o ambiente natural; $12 \%$ relatam que a educação ambiental é uma necessidade para a vida da humanidade; $4 \%$ acreditam que educação ambiental é necessária para saber a importância da reciclagem; e $21 \%$ do total não opinaram sobre o assunto.

Boa parte dos estudos relacionados a percepção está centrado na fenomenologia, na qual a realidade apresenta-se como um grupo de fenômenos altamente complexos, que torna impossível a sua total compreensão (BICUDO, 2000; DEL RIO et al., 1996). Posto que, na maioria das pesquisas em percepção ambiental, o termo percepção evidencia amplo significado, abrangendo os pensamentos fisiológicos além de experiências, memórias, interpretações e expectativas (BICUDO, 2000; DEL RIO, 1991).

Observou-se, no decorrer do trabalho, que assim como nos estudos levantados por Fonseca et al. (2005) e Freitas et al. (2009), 49\% dos entrevistados entende que educação ambiental significa cuidar do meio ambiente. De fato, a concepção dos interlocutores não está errada, necessitando apenas de melhor 
fundamentação, considerando o Artigo 1ํ da Lei no 9.795/1999 conhecida como a Lei de Política Nacional de Educação Ambiental, que diz:

Entendem-se por educação ambiental os processos por meio dos quais o indivíduo e a coletividade constroem valores sociais, conhecimentos, habilidades, atitudes e competências voltadas para a conservação do meio ambiente, bem de uso comum do povo, essencial à sadia qualidade de vida e sua sustentabilidade.

Segundo os Parâmetros Curriculares Nacionais (PCNs) (BRASIL, 2000), a educação ambiental no ensino fundamental e médio deve ser abordada como tema transversal, em todas as séries e disciplinas, garantindo que independente da disciplina o professor deverá inseri-la, de modo a visar a transformação do comportamento pessoal, mudanças de atitude e valores como cidadão, podendo gerar fortes consequências em meio a sociedade, garantindo que todos tenham direitos e oportunidades para usufruir de conhecimentos sobre as questões ambientais notadamente importantes no exercício da cidadania menos antropocêntrica (SARAIVA et al., 2008).

Em 2005, estudos levantados pelo MEC apontaram que a educação ambiental no Brasil vem sendo trabalhada em disciplinas especiais, incluindo o tema ambiental nas disciplinas e através de projetos (ALMEIDA, 2011). Fato que caracteriza a opinião dos interlocutores (14\%), os quais afirmaram entender que educação ambiental significa estudar e conhecer o ambiente natural.

\section{A percepção dos entrevistados quanto à educação ambiental no seu processo de formação}

Quando questionados sobre a educação ambiental em seu processo de formação educacional ou em atividades educacionais, cerca de $55 \%$ dos entrevistados relataram que a educação ambiental tem feito parte da sua formação, sendo que, $37 \%$ admitem que a educação ambiental não tem feito parte do seu processo de formação educacional e $8 \%$ não expressaram opinião neste requisito da pesquisa. Com relação ao questionamento sobre projetos ou atividades desenvolvidas pela escola, 39\% reconheceram que a escola costuma desenvolver projetos ambientais que auxiliem na percepção do ambiente ecológico, $55 \%$ disseram que a escola não costuma desenvolver estes projetos e $6 \%$ não responderam a questão.

Em meio aos questionamentos da pesquisa, verificou-se o discernimento dos participantes quanto a educação ambiental em seu processo de formação ou em atividades educacionais. 55\% dos entrevistados afirmaram acreditar que o assunto está presente em seu desenvolvimento educacional, porém, em meio a visita dos pesquisadores percebeu-se uma grande dificuldade em relação a implementação da metodologia de projetos e ações ambientais interdisciplinares e transversais de modo que poucos professores costumam propor algo, muito em conta da sobrecarga e pouca disponibilidade de tempo, de forma a evidenciar que a educação ambiental ocorre de maneira fragmentada na escola, em paralelo aos estudos realizados por Guimarães (2004), Pires et al. (2010) e Almeida et al. (2012), que evidenciam a mesma proporção apesar de não serem especificamente iguais.

Todavia, o mesmo número de alunos (55\%) afirmaram que a escola não costuma desenvolver projetos ou atividades que exerçam a educação ambiental, evidenciando grande semelhança ao trabalho 
feito por Fonseca et al. (2005) em que o maior número de participantes não se envolveram em projetos ambientais devido à $R \$ 39.788,00$ falta de oportunidade.

Ao analisar o Projeto Político-Pedagógico (PPP) da escola referente ao ano de 2016, especificamente na área de 'projetos desenvolvidos ou em desenvolvimento', foi encontrado apenas um projeto que proporciona a integração junto a educação ambiental. Em semelhança ao levantamento de Silva (2009), os demais projetos, voltados à cultura e esporte, possuem eixos interdisciplinares, mas necessitam de visão teórica para definir metas e nortear as atividades relativas a educação ambiental. Demonstrando que o tema não é considerado um dos principais componentes dos projetos inclusos no PPP, em igualdade ao estudo levantado por Chaves et al. (2015).

Na unidade escolar, os conteúdos voltados a temática ambiental são trabalhados durante as aulas através de debates, confecção de painéis educativos, vídeos, palestras e principalmente livros didáticos. Neste caso, as informações podem está sendo transmitidas por diferentes meios de comunicação e não somente através da mídia expositiva, fato que apresenta grande semelhança ao estudo de Malafaia et al. (2009).

Em relação aos livros didáticos, notou-se que se trata de uma abordagem disciplinar caracterizada pela visão fragmentada e reducionista. Boa parte dos conteúdos abordados nos livros referentes a educação ambiental recebem pouco destaque, sendo revelados de forma secundária, proporção essa que aponta igualdade a investigação feita por Fonseca (2007) em escolas do ensino médio na cidade de Belém/PA. Conforme Dias (2001) nota-se que os livros didáticos não especializados possuem implicações sobre a transparência do tema ambiental na educação, muito em conta das publicações disponíveis aos docentes que empregam um olhar preservacionista, inocente e cientificamente desatualizado.

Os livros se tornaram sinônimo de segurança aos professores, mas não necessariamente garantem segurança na promoção da educação ambiental, em razão de apontar ineficiência em vários casos, estabelecendo a desordem de conteúdos que priorizam o tema ecologia (SATO, 1994). Pesquisas realizadas em contextos semelhantes, tal como Malafaia et al. (2009) enfatizam as mesmas características encontradas neste estudo, apontando que normalmente confundem-se a educação ambiental com ecologia na qual os professores são induzidos a incrementar ações reducionistas com os alunos, trabalhando sempre o desmatamento, efeito estufa, plantio de árvores, poluição, reciclagem e construção de hortas, ações que normalmente se restringem a datas comemorativas.

Levando em conta a realidade do público pesquisado e os possíveis projetos que podem ser desenvolvidos na unidade escolar, verificou-se, na pesquisa realizada por Collioni (2011), a eficácia do projeto semear e a sua contribuição em relação a postura consciente dos alunos e a construção de valores. O projeto trabalha a sensibilidade voltada as questões ambientais, a preservação dos recursos naturais e a sua importância, iniciando-se em sala de aula e contagiando toda a comunidade escolar, tornando-o um projeto que pode ser trabalhado no centro de ensino visitado devido a sua capacidade de aproximação à realidade e a comunidade local. 


\section{Observação dos entrevistados acerca da gestão escolar}

Verificou-se que $20 \%$ do número de entrevistados afirmaram que houveram mudanças na gestão ambiental da escola durante o ano letivo, onde a mesma foi determinante para a transformação em seu pensamento perante a conscientização para a realidade ambiental, alguns interlocutores (10\%) disseram haver mudanças na gestão, em que promoveu a reconstrução da horta, enquanto $33 \%$ declararam que não houve mudanças, por fim, 37\% não opinaram, conforme o ilustrado na figura 3.

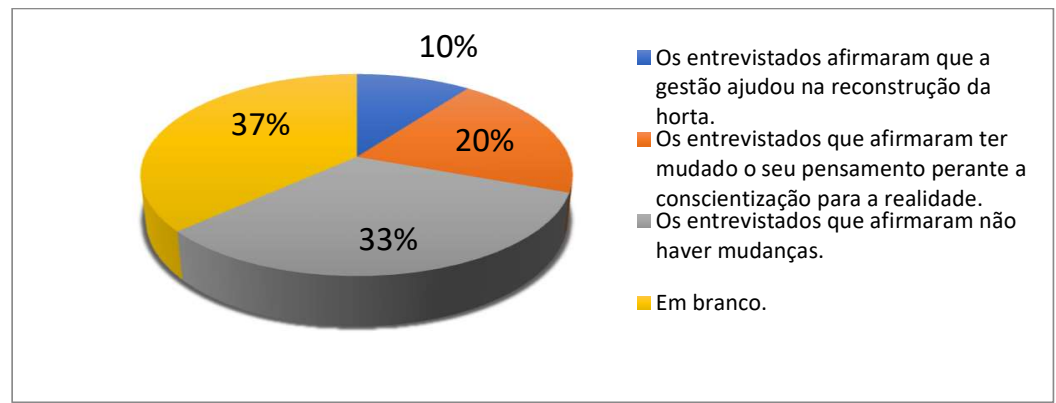

Figura 3: Percentual das respostas dos participantes com relação a sua percepção acerca da gestão escolar na unidade de ensino visitada.

Constatou-se que, para $20 \%$ dos entrevistados, ocorreram mudanças na gestão ambiental escolar durante o ano letivo, fato que, de acordo com os participantes, foi determinante para a transformação em seu pensamento perante a conscientização para com a realidade do ambiente. Embora grande parte acredite nestas transformações, $33 \%$ disseram não perceber mudanças na gestão, corroborando aos dados que apresentaram supremacia no decorrer de toda a pesquisa levando a acreditar que a direção institucional não adota a questão ambiental conforme a orientação dos PCNs, tal como nos levantamentos realizados por Almeida (2007), Saraiva et al. (2008) e Almeida et al. (2012), que verificaram a inserção da educação ambiental em escolas públicas.

Quando questionados sobre a gestão escolar 37\% não expressaram opinião, demonstrando que esses integrantes apresentam incertezas em relação as mudanças que implicam a sua conscientização, dados que, quando somados aos que asseguraram não ter mudado totalizam $70 \%$, número expressivamente maior em relação aos $30 \%$ que admitiram haver mudanças, entre os quais $10 \%$ acreditam que estas transformações foram consequência da sua participação na reconstrução da horta. Claramente uma atividade pontual que não assegura a compreensão da complexidade ambiental devido ao seu caráter desassociado da realidade sociocultural (GUIMARÃES et al., 2012).

De fato, o exercício da educação ambiental nas escolas não se faz de maneira simples e facilitada, muito em conta do ensino tradicionalista ainda presente nas unidades escolares (VIRGENS, 2011). Assim como a falta de autonomia que as mesmas possuem por estarem sujeitas as políticas públicas (TRISTÃO, 2008).

Levando em conta a realidade da escola visitada, para implementar a educação ambiental é necessário a participação de toda a equipe pedagógica tendo em conta o foco nos objetivos educacionais, iniciando-se na construção do PPP e atribuindo ao mesmo a importância do tema ambiental que possibilita 
aos professores trabalhar a questão em sala de aula, já que se trata do documento que norteia as ações da gestão perante a comunidade (VEIGA, 2005). Entretanto, a aplicação da educação ambiental vai além de conceitos e leis, devendo tornar-se dinâmica e operante, na qual se faz importante inserir a cultura, organização política, pensamento social e economia, através de metodologias que facilitem a compreensão (FERNANDES et al., 2012).

Contudo, os PCNs assumem que a educação ambiental se encontra distante de ser uma prática normalmente aceita e aplicada, por implicar alterações adversas e nada inócuas (BRASIL, 2001). Sabendo que a temática ambiental se faz de maneira ineficiente na escola, percebeu-se ao longo das entrevistas que os participantes acreditam ser responsabilidade dos professores de biologia e geografia, o que demonstra certa resistência por parte de alguns docentes que adotam o ensino tradicional e consequentemente não incluem este conteúdo em suas disciplinas, fato encontrado também nas investigações de Telles et al. (2002) e Gonçalves et al. (2009).

Nesse contexto, o professor como mediador do conhecimento possui uma das tarefas mais importantes na aplicação da educação ambiental, uma vez que, a sua ação em sala é uma das maneiras de conduzir o conhecimento a comunidade (SANTOS, 2007). Contudo, o professor deve ser capacitado para ensinar a educação ambiental em sala, necessitando estar preparado para decifrar as informações, articular entre as disciplinas e auxiliar os discentes na construção de um saber significativo (GUIMARÃES, 2004; VIRGENS, 2011; COSTA, 2002). De modo que a educação ambiental bem trabalhada possua relação com os educandos e o seu cotidiano (MINC, 2008).

Considerando as conclusões de levantamentos relacionados a educação ambiental, a escola pode utilizar de projetos socioambientais para desenvolver a temática juntamente com a comunidade, utilizando a interdisciplinaridade e transversalidade que proporcionam um leque de possibilidades para o incremento do Projeto Político Pedagógico (PPP) (TRAJBER et al., 2006).

Cabe ressaltar a importância da participação dos pais e da comunidade local dentre as proposições da escola (TAILLE, 2004), a mesma afirma que a participação dos pais nos projetos desenvolvidos não se enquadra no desejável. Apesar da dificuldade, cabe a escola persistir e melhorar os seus respectivos projetos, como o projeto cultural mencionado em seu PPP que trabalha a cultura brasileira, mas que pode receber o eixo interdisciplinar proporcionando trabalhar a educação ambiental, sua importância em nosso cotidiano e a influência do ambiente sobre a vida.

Há ainda o projeto "Faça uma criança feliz" que consiste na doação de brinquedos às crianças de comunidades carentes, podendo trabalhar sobre o consumismo e como este afeta o ambiente, como confeccionar brinquedos através de recursos ecológicos visando o reaproveitamento de materiais e conscientizando sobre a importância de eliminar do ambiente natural materiais de difícil degradação, além de propagar uma boa ação e influenciar sob a percepção ambiental do indivíduo, incluindo nesse processo toda a comunidade, os pais, os alunos, professores e os gestores. Todavia, é importante destacar que a escola 
não é o único agente educador, de modo que a família, mídia e a sociedade exercem influências sobre o desenvolvimento dos alunos (MARÇAL, 2005).

\section{CONCLUSÃO}

Em vista dos argumentos apresentados, através da análise das informações coletadas, concluiu-se que a educação ambiental na escola se apresenta de forma superficial. Apesar de estar presente em alguns eventos não se dá como um dos principais temas abordados durante o ano letivo, o que compromete a percepção ambiental dos alunos e profissionais que compõem a comunidade escolar. Percebe-se que a maioria dos professores demonstram dificuldades em trabalhar a educação ambiental, assim como transversalizar e interdisciplinarizar durante as aulas, em consequência da elaboração dos PPPs que não contemplam a temática e da fragmentação que provém do ensino tradicional. É imprescindível que todos se conscientizem da necessidade de mudanças neste quadro, a escola como modeladora social deve contribuir para a formação de indivíduos capazes de perceber a influência das suas ações perante o ambiente.

Desenvolver a educação ambiental em suas atividades exige atribuir importância ao tema, fato que se inicia na construção do PPP de forma a incluir neste documento projetos, ações e medidas coletivas que quebrem a fragmentação e o individualismo, os professores que apresentam dificuldades com a questão transversal e interdisciplinar necessitam de capacitação para desenvolverem conceitos e atribuições necessárias as práticas docentes atuais, revertendo a teoria transversal em prática, de forma que através dos alunos seja possível atingir a comunidade, devido ao fato de levarem para casa os conhecimentos adquiridos na escola que podem influenciar na postura dos pais. Em virtude de tudo o que foi mencionado, acredita-se que a educação ambiental não constitui uma tarefa exclusiva da escola, mas sim dos alunos e comunidade que formam uma equipe transformadora capaz de reverter o cenário ambiental em que vivemos, garantindo recursos para as próximas gerações.

\section{REFERÊNCIAS}

ALMEIDA, A. S. V.. A inclusão da educação ambiental nas escolas públicas do estado de Goiás: o caso dos PRAECs. Dissertação (Pós-Graduação em Educação, Ciências e Matemática) - Universidade Federal de Goiás, Goiânia, 2011.

ALMEIDA, A.. Que papel para as Ciências da Natureza em Educação Ambiental? Discussão de ideias a partir de resultados de uma investigação. Revista

Electrónica de Enseñanza de las Ciências, v.6, n.3, p.522-537, 2007.

ALMEIDA, O. S.; MACEDO, D. F.; SANTOS, V. C.; ANJOS, K. F.. Educação Ambiental e a prática educativa: estudo em uma escola estadual de Divisa Alegre/MG. Revista Metáfora Educacional, n.13, p.156-173, 2012.
ARAÚJO, M. I. O.; SOARES, M. J. N.. Educação ambiental: o consumo de práticas pedagógicas consolidadas na pesquisa de professores em escolas públicas. Aracaju: Criação A\&C, 2010.

BICUDO, M. A. V.. A pesquisa qualitativa fenomenológica à procura de procedimentos rigorosos. In: BICUDO, M. A. V.. Fenomenologia: confrontos e avanços. São Paulo: Cortez, 2000. p.70102.

BRASIL. Lei n.9795 de 27 de abril de 1999. Dispõe sobre a educação ambiental, institui a Política Nacional de Educação Ambiental e dá outras providências. Brasília: 1999. 
BRASIL. Ministério da Educação. Parâmetros Curriculares Nacionais: Meio Ambiente e Saúde. v.9. Brasília: MEC, 2000.

BRASIL. Ministério da Educação. Parâmetros Curriculares Nacionais: meio ambiente e saúde. 3 ed. Brasília: 2001.

BRASIL. Ministério da Educação. Parâmetros Curriculares Nacionais: ensino médio. Brasília: MEC, 1999.

CALDAS, A. L. R.. Percepção Ambiental dos usuários do Parque Estadual da Serra de Caldas Novas-Goiás com relação à sua inserção no Meio Ambiente: métodos de campo em Ecologia. Brasília: 2003.

CARVALHO, I. C. M.. Educação Ambiental: a formação do sujeito ecológico. 2 ed. São Paulo: Cortez, 2006.

CHAVES, T. F.; BARBOSA L. C. A.. Análise da inserção da educação ambiental em projetos políticospedagógicos de escolas públicas de São Miguel do Oeste/SC. Monografias Ambientais, Santa Maria, v.14, n.2, p.100-116, 2015.

COLLIONI, M. F. M.. A Educação Ambiental nas escolas. Osório: 2011.

COSTA, P. A.. Fundamental Educação Ambiental. Revista do Senac, Rio de Janeiro, n.1, p.34-37, 2002.

CUBA, M. A.. Educação Ambiental nas escolas. ECCOM, v.1, n.2, p. 23-31, 2010.

CUNHA, H. F.; VALE, M. S.; JUNIOR, C. A. S.; CAMPOS, R. F.; CARLOS, L. O.. Conhecimento empírico dos moradores da comunidade do entorno do Parque Municipal da Cachoeirinha (Iporá-Goiás). Acta Scientiarum. Biological Sciences, Maringá, v.29, n.2, p.203-212, 2007.

DEL RIO, V.. Desenho urbano e revitalização na área portuária do Rio de Janeiro: a contribuição ao estudo da percepção ambiental. Tese (Doutorado em Arquitetura e Urbanismo) - Universidade de São Paulo, 1991.

DEL RIO, V.; OLIVEIRA, L.. Percepção ambiental: a experiência brasileira. São Paulo: Studio Nobel, 1996.

DIAS, G. F.. A situação da Educação Ambiental no Brasil é fractal. In: BRASIL. Ministério da Educação. Panorama da Educação Ambiental no Ensino Fundamental. Brasília: MEC, 2001.

DIAS, G. F.. Educação Ambiental: princípios e práticas. 9 ed. São Paulo: Gaia, 2004.
FERNANDES, F. H. M.; MEDEIROS, J. A.. Educação ambiental e a construção de valores: vivenciando o ser e o fazer do ensino fundamental. In: CONGRESSO NORTE-NORDESTE DE PESQUISA E INOVAÇÃO, 7. Anais. Recife: IFPE, 2012.

FONSECA, M. J. C. F.. A biodiversidade e o desenvolvimento sustentável nas escolas do ensino médio de Belém (PA). Educação e Pesquisa, v.33, n.1, p.63-79, 2007.

FONSECA, V. L. B.; COSTA, M. F. B.; COSTA, M. A. F.. Educação ambiental no ensino médio: mito ou realidade. Revista Eletrônica do Mestrado e Educação Ambiental, Rio Grande do Sul, v.15, p.146, 2005.

FREITAS, A. C.; SANTOS, J. E. O.; BARRETO, L. V.. Educação ambiental no ensino de jovens e adultos. Enciclopédia Biosfera, v.5, p.1-11, 2009.

GOMES, D. V.. Educação para o consumo ético e sustentável. Revista Eletrônica do Mestrado em Educação Ambiental, Porto Alegre, v.16, p.18-31, 2006.

GONÇALVES, G. N.; CRUZ-SILVA, C. T. A.. Análise dos conhecimentos sobre problemas ambientais dos alunos do ensino fundamental e ensino médio da rede pública. Revista Eletrônica do Mestrado em Educação Ambiental, v.23, p.29-43, 2009.

GUEDES, J. C. S.. Educação ambiental nas escolas de ensino fundamental: estudo de caso. Garanhuns: Editora do Autor, 2006.

GUIMARÃES, M.. A formação de educadores ambientais. Campinas: Papirus, 2004.

GUIMARÃES, M.. Educação ambiental crítica. In: LAYRARGUES, P. P.. Identidades da educação ambiental brasileira. Brasília: MMA, 2004. p.25-34.

GUIMARÃES, S. S. M.; INFORSATO, E. C.. A percepção do professor de Biologia e a sua formação: a Educação Ambiental em questão. Ciência \& Educação, v.18, n.3, p.737-754, 2012. DOI: http://doi.org/10.1590/S1516$\underline{73132012000300016}$

IBGE. Instituto Brasileiro de Geografia e Estatística. Estimativas populacionais para os municípios e para as Unidades da Federação brasileiros. Rio de Janeiro: IBGE, 2015.

IBGE. Instituto Brasileiro de Geografia e Estatística. Histórico da Cidade Guaraí/TO. Rio de Janeiro: IBGE, 2013.

KINDELL, E. A. I.; FABIANO, W. S.; MICAELA, Y.. Educação ambiental: vários olhares e várias práticas. 2 ed. Curitiba: Mediação, 2006. 
LIMA, W.. Aprendizagem e classificação social: um desafio aos conceitos. Revista do Instituto Superior de Estudos Pedagógicos, v.3, n.1, 2004.

MALAFAIA, G.; ROGRIGUES, A. S. L.. Percepção ambiental de jovens e adultos de uma escola municipal de ensino fundamental. Revista Brasileira de Biociências, v.7, n.3, 2009.

MARÇAL, M. P. V.. Educação ambiental e representações sociais de meio ambiente: uma análise da prática pedagógica no ensino fundamental de Patos de Minas - MG. Dissertação (Mestrado em Geografia) - Universidade Federal de Uberlândia, Uberlândia, 2005.

MARCONI, M. A.; LAKATOS, E. M.. Fundamentos da metodologia científica. 6 ed. São Paulo: Atlas, 2008.

MAURÍCIO, S. S.. Educação ambiental: uma análise comparativa entre a multieducação e os PCNs. Dissertação (Mestrado em Educação) - Universidade Estácio de Sá, Rio de Janeiro, 2009.

MICHEL, M. H.. Metodologia da pesquisa em ciências sociais: Um guia prático para acompanhamento da disciplina e elaboração de trabalhos monográficos. São Paulo: Atlas, 2005.

MINC, C.. Ecologia e cidadania. 2 ed. São Paulo: Moderna, 2008.

PALMA, I. R.. Análise e percepção ambiental como instrumento ao planejamento da educação ambiental. Dissertação (Mestrado em Engenharia) Universidade do Rio Grande do Sul, Porto Alegre, 2005.

PIRES, A. G.; FARIA, W. F.. A Educação Ambiental e o Projeto Político-Pedagógico: Articulações no cotidiano em uma escola estadual de Cruzeiro do Sul/AC.

Revista de Estudos Universitários, Sorocaba, v.36, n.3, p. 201-227, 2010.

QUADROS, A.. Educação Ambiental: iniciativas populares e cidadania. Monografia (Especialização em Educação Ambiental) - Universidade Federal de Santa Maria, Rio Grande do Sul, 2007.

SANTOS, E. M.; FARIA, L. C. M.. O educador e o olhar antropológico. Revista do Instituto Superior de Estudos Pedagógicos, v.3, n.1, 2004.
SANTOS, E. T. A.. Educação ambiental na escola: conscientização da necessidade de proteção da camada de ozônio. Monografia (Pós-Graduação em Educação Ambiental) - Universidade Federal de Santa Maria, Porto Alegre, 2007.

SARAIVA, V. M.; NASCIMENTO, K. R. P.; COSTA, R. K. M.. A prática Pedagógica do Ensino de Educação Ambiental nas Escolas Públicas de João Câmara - RN. Holos, v.24, n.2, 2008.

SATO, M.. Como o ambiente é escrito. In: ENCONTRO PERSPECTIVAS DO ENSINO DA BIOLOGIA, 5. Anais. São Paulo, USP, 1994.

SILVA, J. R. N.. Educação ambiental no contexto do projeto político-pedagógico de duas escolas estaduais de Manaus/AM. In: CONGRESSO DE PESQUISA E INOVAÇÃO DA REDE NORTE E NORDESTE DE EDUCAÇÃO TECNOLÓGICA, 4. Anais. Belém: IFRN, 2009.

TAILLE, Y.. A sociedade enfrenta problemas para os quais a escola é a única solução. Jornal do Marista, Belo Horizonte, n.7, p.7-8, 2004.

TELLES, M. Q.; ROCHA, M. B.; PEDROSO, M. L. Vivências integradas com o meio ambiente. São Paulo: Sá, 2002.

TRAJBER, R.; MENDONÇA, P. R.. Educação na diversidade: o que fazem as escolas que dizem que fazem educação ambiental. Brasília: UNESCO, 2006.

TREVISOL, J. V.. A educação em uma sociedade de risco: tarefas e desafios na construção da sustentabilidade. Joaçaba: UNOESC, 2003.

TRISTÃO, M.. A Educação Ambiental na formação de professores: redes de saberes. São Paulo: Annablume, 2008.

VEIGA, A.; AMORIM, E.; BLANCO, M.. Um retrato da presença da educação ambiental no ensino fundamental brasileiro: o percurso de um processo acelerado de expansão. Brasília: Instituto Nacional de Estudos e Pesquisas Educacionais Anísio Teixeira, 2005.

VIRGENS, R. A.. A Educação Ambiental no ambiente escolar Monografia (Graduação em Biologia) Universidade de Brasília, Brasília, 2011.

WHYTE, A. V. T.. Guidelines for fields studies in environmental perception. Paris: UNESCO, 1977. 